\title{
Catastrophic healthcare expenditure and coping strategies among patients attending cancer treatment services in Addis Ababa, Ethiopia
}

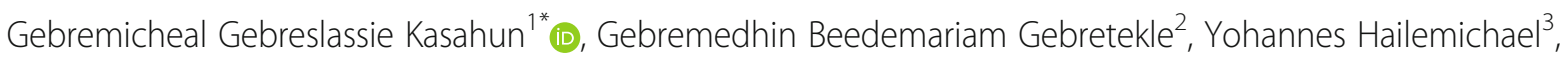
Aynalem Abraha Woldemariam ${ }^{4}$ and Teferi Gedif Fenta ${ }^{2}$

\begin{abstract}
Background: With the rapid increase in magnitude and mortality of cancer, which is costly disease to manage, several patients particularly in developing countries are facing a huge financial burden. The study aimed to examine the incidence of catastrophic health expenditure (CHE), identify associated factors and coping strategies among patients attending cancer treatment services in Addis Ababa, Ethiopia.

Methods: A hospital-based cross-sectional survey of patients with cancer was conducted in public and private hospitals between January and March 2018. Data was collected using a structured questionnaire. All direct medical and nonmedical expenditures were measured and reported as expenditure (US\$) per patient (1US\$ equivalent to 23.41 Ethiopian Birr). The CHE was estimated using a threshold of 10\% of annual household income.

Results: A total of 352 (response rate of 87.1\%) participants were interviewed. Majority (73.3\%) of the respondents were females; most (94\%) from public hospitals and their mean ( \pm SD) age was $48 \pm 13.2$ years. Vast majority (74.4\%) of patients experienced CHE with mean overall expenditure of $\$ 2366$ per patient (median: \$1708). Medical expenditure shared the highest overall expenditure (83.6\%) with mean medical and nonmedical costs of $\$ 1978$ (median: \$1394) and \$388 (median: \$222), respectively. Patients who took greater than six cycles of chemotherapy (AOR: $3.64 ; 95 \%$ Cl: 1.11-11.92), and age (AOR: 1.03; 95\% Cl: 1.01-1.06) were significantly associated with CHE. Household saving (85.5\%) followed by financial support received (43.0\%) was the main coping strategy.

Conclusion: A substantial number of patients with cancer were exposed to CHE with a considerable medical expenditure. Hence, in addition to the popularization of the already introduced health insurance scheme, other better prepayment or insurance mechanisms should also be considered to ensure financial risk protection and realize universal health coverage for patients with cancer.
\end{abstract}

Keywords: Catastrophic health expenditure, Coping strategy, Out of pocket expenditure, Cancer

* Correspondence: gebremicheal.kassahun@gmail.com

'Department of Pharmacy, College of Health Sciences, Aksum University, Aksum, Tigray, Ethiopia

Full list of author information is available at the end of the article

(c) The Author(s). 2020 Open Access This article is licensed under a Creative Commons Attribution 4.0 International License, which permits use, sharing, adaptation, distribution and reproduction in any medium or format, as long as you give appropriate credit to the original author(s) and the source, provide a link to the Creative Commons licence, and indicate if changes were made. The images or other third party material in this article are included in the article's Creative Commons licence, unless indicated otherwise in a credit line to the material. If material is not included in the article's Creative Commons licence and your intended use is not permitted by statutory regulation or exceeds the permitted use, you will need to obtain permission directly from the copyright holder. To view a copy of this licence, visit http://creativecommons.org/licenses/by/4.0/ The Creative Commons Public Domain Dedication waiver (http://creativecommons.org/publicdomain/zero/1.0/) applies to the data made available in this article, unless otherwise stated in a credit line to the data. 


\section{Background}

Out of pocket (OOP), healthcare financing leaves households exposed to the risk of unanticipated catastrophic financial expenditures that absorb a large share of the household budget [1]. Catastrophic health expenditure (CHE) is healthcare spending that exceeds some specified critical level of tolerance or threshold from the household total income in a given specified period [2-5]. According to Wagstaff and Van Doorslaer [4], the incidence of CHE is estimated from the fraction of OOP payments, which exceeds a certain threshold, usually $10 \%$ of total household annual income, often for one-year interval. It occurs when the available health service is mainly dependent on OOP payment, households have low capacity to pay, and if there is no prepayment [6]. CHE is highly pronounced when the diseased household member is at a productive age, and when the individual is the primary source of household income [1].

Cancer is one of the chronic non-communicable diseases with a high likelihood of imposing CHE [7]. It is a collection of conditions in which cells change, multiply and metastasize out of control in the body. Lung, cervical, prostate, stomach, colorectal, liver, and breast are among the most prevalent cancer types in the world [8]. According to the world health organization (WHO) global cancer report, about 14.1 million new cancer cases and 8.2 million deaths occurred in 2012 globally. The global burden of cancer is projected to continue, particularly in developing countries. It is projected to increase to 19.3 million new cancer cases per year by 2025 worldwide [9]. It imposed the most devastating economic impact in 2010; about 808 million people had incurred catastrophic health spending worldwide [10]. Moreover, due to premature death and disability, about $\$ 895$ billion of economic impact was debited in 2008 globally without including the direct medical cost, which could further increase the financial lost [11].

Like other countries, especially low-middle-income countries [12], there is a rapid increase in the magnitude and mortality of cancer in Ethiopia. Besides, it is believed that cancer is costly to manage; as a result, several patients are facing a huge financial burden. Intending to share financial risks and improving access to essential services, Ethiopia's government had developed a strategic plan for establishing and expanding mandatory health insurance [13]. Cancer is among the services covered by the insurance scheme, but its coverage remains very low in pilot phase [14]. As a result, the majority of the population is still dependent on OOP payment for healthcare service. On the other hand, there is limited evidence about the level of CHE and OOP healthcare expenditure for the diagnosis and treatment of cancer in Ethiopia $[15,16]$. Therefore, the study aimed to examine the incidence of $\mathrm{CHE}$, identify associated factors and coping strategies among patients attending cancer treatment services in Addis Ababa, Ethiopia.

\section{Methods \\ Study area and study design}

Hospital-based cross-sectional study design was employed. The study was conducted in Addis Ababa, the capital city of Ethiopia (the second-most populous country in Africa) and headquarters of African Union. Addis Ababa has 13 public hospitals, 32 private hospitals, and 93 health centers. From ten cancer diagnostic and treatment centers, about 150-200 new cases of cancer are registered monthly. Each month, about 1200 cancer patients visit these health facilities either for follow up or treatment. From the public hospitals, Tikur Anbessa Specialized Hospital (TASH) is the biggest teaching and referral public hospital with the highest number of cases. The study was conducted in TASH and three private hospitals (Hallelujah, Bete-Zata and Leghar General Hospitals) between January and March 2018.

\section{Study population and sampling procedure}

The source population was all cancer patients attending treatment service in Addis Ababa healthcare facilities. Histological and/or pathologically confirmed cancer patients, patients who took at least one of the anticancer therapy options (chemotherapy, radiotherapy or hormonal/others), patients with a regular follow up for the last 1 year preceding the interview date, and with no comorbidity and were volunteer to participate, constituted the study participants.

The sample size was determined using a single proportion population formula [17], and a total of 404 participants were recruited from one government hospital (TASH) and three private hospitals. TASH was included as it is the sole oncology referral and radiotherapy center in the country and it has also the highest number of cancer patients. Private hospitals were also selected based on their voluntariness to be enrolled and patient load. Participants were recruited using a convenience sampling technique and the number of participants to be drawn from each hospital was decided based on proportion to patient load.

\section{Data collection and management}

A structured questionnaire (S1 Table 1 Data collection instrument) was developed from the WHO SAGE (Study of Global Ageing and Adult Health) study [18] and other relevant literatures $[15,19,20]$. This English version of the questionnaire was translated into Amharic (national language) and back-translated to English to ensure consistency. The questionnaire was pretested before the commencement of the data collection process. 
Appropriate modification and validation process were made based on the result of the pretest.

The data collection tool was consisted of six parts: (1) socio-demographic characteristics (age. Gender, occupation, marital status, education level and household size); (2) medical information (such as type of cancer, time of first diagnosis, treatment initiated, type of treatments taken and history of visit to a private health facility); (3 and 4) expenditures on the outpatient and inpatient services (including consultation, investigation, medicine and other relevant costs); (5) household essential consumption and income (weekly food and others spending, monthly house rent, cloths, transport and other charges, annual education payment, durable materials e.g., television, phone, furniture, vehicles, ceremonies and others spending, overall household yearly expenditure and income, and patient income if available); and (6) households financial situation outlook (rate of financial burden, coping mechanisms taken and its amount). Besides, patient medical charts were reviewed to collect relevant clinical information, investigations and treatments taken which also helped in estimating patient treatment/diagnostic expenditures.

Data was collected in a face-to-face exit interview and daily supervision was made by the principal investigator to ensure its completeness and consistency.

\section{Measurements}

The magnitude of CHE was estimated using Wagstaff and Van Doorslaer [4] approach. When previous oneyear patient households' OOP expenditure for cancer care exceeded $10 \%$ of total annual household income, it was considered catastrophic. The overall, outpatient and inpatient cancer diagnostic and treatment service expenditures of the last 12 months were estimated and presented as average expenditure per patient. Therefore, these households incurred a catastrophic expenditure assumed as catastrophic payment headcounts $\left(\mathrm{H}_{\text {cat }}\right)$.

Healthcare service OOP expenditure is a direct payment made to healthcare providers on receiving a service excluding prepayment, reimbursement, and other sources of payment mechanisms $[4,5,21]$. However, households can use different coping strategies to solve their financial burden. Coping mechanisms may include any means of income obtained from household member and other savings including Eqqub and Iddir, any financial support from relatives, religious organization and other sources which are non-refundable. Income derived from selling household assets like property, livestock, jewellery, and other household items; and any types of borrowing from financial institutions or individuals could be sources of finance to cover any medical and non-medical expenses. These coping mechanisms could be rearranged as; savings, financial support, selling assets, and borrowings [7, 20]. Households had used different coping strategies, which can be classified into two categories: expenditure covered by only the households themselves and by other mechanisms to estimate the CHE level of cancer care.

Households' subjective rate of self-reported financial burden was assessed by asking respondents to rate their current household economic situation compared to the past; as very good, good, medium/similar, bad and worse. Later, they were reclassified as "manageable" for very good, good and medium/similar and "unmanageable" for bad and worse.

Expenditure was estimated as all costs spent for cancer care before the interview time in the last year of medical service upon possible probing approaches to minimize recall bias. This expenditure includes both medical and non-medical expenses. Medical expenses were all expenditures related to consultation, investigation, medicine, bed and traditional medicine. On the other hand, nonmedical cost includes transportation, food and other accommodation expenditures associated with the patient care. Expenses were also categorized as outpatient expenditures (consultation, investigation, medicine, and other spending related to outpatient care), and inpatient expenditures (consultation, investigation, medicine, bed and other expenses associated with inpatient care). There are controversies on estimating cost data, especially when the data have a skewed nature. Some studies reported "mean" as a reasonable choice, although it could be affected by the extreme values [22, 23]. However, others studies preferred to report using the median since it is not affected by skewness, although it only shows the position of the distribution [24]. Hence, we used both mean and median measurements to provide a full picture of the estimation, which might ease health policy decision making and resource allocation.

Household income and expenditure were measured based on respondents' self-reported daily or monthly income and expenditure. Participants with in-kind income were approached for their type of income and amount. The in-kind income was then changed to monetary terms based on their current value to the local market. Besides, all expenditures were measured, and costs were reported as an expenditure (US\$) per patient (1US\$ equivalent to 23.41 Ethiopian Birr).

\section{Covariates}

Socio-demographic, clinical and economic variables including type of health facility (private and public), kind of cancer (breast cancer, colorectal cancer, cervical cancer, nasopharyngeal cancer (NPC) and others), cycles of chemotherapy taken (less than or equal to three cycles, four to six cycles, more than six cycles and on other treatment options), history of a visit to a private health 
facility, gender, marital status,residence (from Addis Ababa and outside of Addis Ababa), the level of education, occupation, income, and expenditure were the variables considered as covariates in the analysis.

\section{Statistical analysis}

Data were coded, entered in to, and analyzed using STATA version 14 (https://www.stata.com/stata14/). Descriptive statistics such as mean, median, standard deviation (SD) and Inter-Quartile Range (IQR) were used to compute socio-demographic, clinical and economic characteristics. Hosmer-Lemeshow test was employed for the goodness of fit test of the logistic regression model. A multivariable logistic regression model was used to assess the relationship between $\mathrm{CHE}$ and potential explanatory variables. The significance level was set at 5 and $95 \%$ confidence interval (CI).

\section{Results}

\section{Socio-demographic and clinical information}

A total of 404 participants were approached, and 352 study participants were interviewed, with a response rate of $87.1 \%$. The majority $(73.3 \%)$ of the patients were females, and $285(81.0 \%)$ were married. Most (94\%) of the respondents were from public hospitals (Table 1). More than three-fourth $(85.2 \%)$ of the study participants were in the productive age category, and their mean $( \pm \mathrm{SD})$ age was $48( \pm 13.2)$ years (ranged 19 to 87 years).

More than one-third (36.9\%) of the participants were breast cancer patients, followed by cervical cancer 58 (16.5\%) and colorectal cancer 46 (13.1\%). The majority (89.0\%) of patients have taken chemotherapy on their treatment course, and 155 (44.0\%) of them were on 4-6 cycles of chemotherapy. All patients have used supportive treatments. The majority $(63.4 \%)$ of respondents had a history of visit at private health facilities during the course of the disease (Table 2).

\section{Overall, outpatient and inpatient services expenditure}

The average overall expenditure per patient in the last one-year was estimated to be \$2366 (SD: \$4262), median: \$1709 (IQR: \$1153-2424). The inpatient services accounted for two-thirds of the total expenditure with a mean cost of \$1584 (SD: \$4002), and a median of \$1067 (IQR: \$641-1580) per patient. The remaining expenditure was spent on outpatient service, with a mean of $\$ 782$ (SD: $\$ 1468$ ) and a median of $\$ 557$ (IQR: \$256-940).

The overall mean expenditure of patients with colorectal cancer who attended private hospitals, who had a history of visit at private health facilities, and those living out of Addis Ababa was higher than their counterparts (Table 3).
Table 1 Socio-demographic and economic characteristics among patients attending cancer treatment services in Addis Ababa, Ethiopia 2018

\begin{tabular}{|c|c|c|}
\hline Characteristics & Frequency (N) & Percentage (\%) \\
\hline \multicolumn{3}{|l|}{ Type of health facility } \\
\hline Public & 331 & 94.0 \\
\hline Private & 21 & 6.0 \\
\hline \multicolumn{3}{|l|}{ Gender } \\
\hline Female & 258 & 73.3 \\
\hline Male & 94 & 26.7 \\
\hline Age (mean, \pm SD) & $48^{\mathrm{a}}$ & $13.2^{\mathrm{b}}$ \\
\hline \multicolumn{3}{|l|}{ Marital status } \\
\hline Married & 285 & 81.0 \\
\hline Single & 34 & 9.6 \\
\hline Divorced & 19 & 5.4 \\
\hline Widowed & 14 & 4.0 \\
\hline \multicolumn{3}{|l|}{ Residence } \\
\hline Out of Addis Ababa & 209 & 59.4 \\
\hline Addis Ababa & 143 & 40.6 \\
\hline \multicolumn{3}{|l|}{ Education } \\
\hline No formal education ${ }^{c}$ & 127 & 36.1 \\
\hline College/certificate and above & 122 & 34.6 \\
\hline Grade 9-12 & 69 & 19.6 \\
\hline Grade 1-8 & 34 & 9.7 \\
\hline \multicolumn{3}{|l|}{ Occupation } \\
\hline Housewife/Husband & 139 & 39.5 \\
\hline Employed (private/government) & 102 & 29.0 \\
\hline Own private business & 49 & 13.9 \\
\hline Retired & 36 & 10.2 \\
\hline Others $^{\mathrm{d}}$ & 26 & 7.4 \\
\hline \multicolumn{3}{|l|}{ Household economic income quintile } \\
\hline Lowest & 74 & 21.0 \\
\hline Second & 74 & 21.0 \\
\hline Middle & 64 & 18.2 \\
\hline Fourth & 71 & 20.2 \\
\hline Highest & 69 & 19.6 \\
\hline \multicolumn{3}{|c|}{ Household economic expenditure quintile } \\
\hline Lowest & 71 & 20.2 \\
\hline Second & 70 & 19.9 \\
\hline Middle & 72 & 20.5 \\
\hline Fourth & 85 & 24.1 \\
\hline Highest & 54 & 15.3 \\
\hline
\end{tabular}

a age (Mean),

b: age (SD = Standard deviation),

c: include illiterates and individuals able to read and write but not attended formal education,

d: include individuals who are not employed/stopped to work 
Table 2 Clinical information of patients attending cancer treatment services in Addis Ababa, Ethiopia 2018

\begin{tabular}{lll}
\hline Clinical variables & $\mathrm{N}$ & $\%(95 \% \mathrm{Cl})$ \\
\hline Type of cancer & 130 & $36.9(32.0-42.1)$ \\
Breast cancer & 58 & $16.5(13.0-20.7)$ \\
Cervical cancer & 46 & $13.1(9.9-17.0)$ \\
Colorectal cancer & 13 & $3.7(2.2-6.3)$ \\
NPC $^{\text {a }}$ & 105 & $29.8(25.3-35.0)$ \\
Others $^{\text {b }}$ & & \\
Type of treatments taken & \\
Supportive treatment & 352 & 100.0 \\
Chemotherapy & 313 & $89.0(85.2-91.8)$ \\
Surgery & 201 & $57.1(51.8-62.2)$ \\
Radiotherapy & 176 & $50.0(44.8-55.2)$ \\
Hormonal & 80 & $22.7(18.6-27.4)$ \\
Cycle of treatment taken & & \\
4-6 cycles & 155 & $44.0(38.9-49.3)$ \\
1-3 cycles & 97 & $27.6(23.1-32.5)$ \\
$>6$ cycles & 61 & $17.3(13.7-21.7)$ \\
On other treatment options & 39 & $11.1(8.2-14.8)$ \\
Private health facility visit history & & $63.4(58.2-68.2)$ \\
Yes & 223 & $36.6(31.8-41.8)$ \\
No & 129 & \\
\hline
\end{tabular}

a: NPC Nasopharyngeal cancer,

b: Other cancer types (including skin, oral, lung, liver, esophageal, bone, Hodgkin lymphoma, non-Hodgkin lymphoma, thyroid and other unspecified tumors, confirmed on histological and/or pathologically exam)

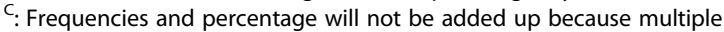
responses were possible

\section{Medical and non-medical expenditure}

The direct mean and median medical expenditures per patient in the last year was estimated to be $\$ 1978$ (SD: \$3554) and \$1394 (IQR: \$917-1982), respectively. On the other hand, the patients had a mean and median non-medical expenditure of \$388 (SD: \$993) and \$222 (IQR: \$122-461), respectively. The medical spending constituted the highest expenditure (83.6\%), taking a large share of the overall expenditure. The mean cost on traditional medicines was also estimated to be $\$ 7$ (SD: $\$ 65)$.

\section{The magnitude of catastrophic healthcare expenditure}

The average headcount adult equivalent income and expenditure was found to be $\$ 1821$ (median: \$1220) and \$1111 (median: \$949) per year, respectively. The mean annual unadjusted household income and expenditure was estimated to be $\$ 4997$ (median: \$3076) and $\$ 3006$ (median: \$2563) per year, respectively. The incidence of incurring CHE was 74.4\% (95\%, CI: 69.6-78.7). Patients in the fourth income quintile had faced higher CHE. Regarding the expenditure quintile, patients in the middle quintile had encountered higher catastrophic cancer care expenditure (Table 4).

Based on participant's self-report, it was estimated that 69\% (95\% CI: 64.0-73.7) of patients' households faced with an unmanageable financial burden which could lead them to a financial crisis.

\section{Factors associated with catastrophic health expenditure}

The multivariable logistic regression analysis revealed that taking greater than six cycles of chemotherapy (AOR: 3.64; 95\% CI: 1.11-11.92), and age (AOR: 1.03; 95\% CI: 1.01-1.06) were factors statistically associated with CHE among cancer patients. In this regard, the tendency to encounter $\mathrm{CHE}$ of cancer care was associated with older age and an increased number of cycles of chemotherapy (Table 4).

\section{Financial burden coping strategies of cancer diagnosis and treatment}

The majority of households had used their household savings $(85.5 \%)$ for healthcare payments. However, a considerable percentage (43\%) of households have received substantial financial support from their relatives, religious and other non-governmental organizations to cover the financial burden imposed on the household. The remaining expenditure was covered by selling assets and borrowings, as illustrated in Table 5.

\section{Discussion}

This study is the first to assess the incidence of CHE, associated factors, and coping strategies for cancer care in Ethiopia. The average overall cancer care expenditure was half of the average unadjusted household annual income and nearly three-fourth of the average unadjusted household yearly spending, which is higher than that of patients in Australia [25]. However, it was lower than the findings of other studies in which patients spent $59.9 \%$ of annual household income [19]. The overall expenditure was very high compared to the per capital income of the population of Ethiopia [26], indicating that uncountable numbers of patients are at home and are dying without getting any treatment and diagnostic services because of the catastrophic expenditure.

Similar to a study reported by Pourreza et al [27], the present research showed that the payment for treatment of colorectal cancer was higher than other types of cancer. The reason being the extended duration of therapy and multiple combination regimens is required to treat colorectal cancer patients, which could result in higher OOP expenditure [28].

Our study found that the level of $\mathrm{CHE}$ was very high compared to what was reported from cancer patients in Korea (39.8\%) [29]. Besides, although direct comparison seems infeasible because of the different threshold level 
Table 3 Mean overall expenditure per patient by different subgroups among patients attending cancer treatment services in Addis Ababa, Ethiopia 2018

\begin{tabular}{|c|c|}
\hline Subgroup variables & Mean overall expenditure per patient (SD) (\$) \\
\hline \multicolumn{2}{|l|}{ By type of cancer } \\
\hline Breast cancer & $2325(2776)$ \\
\hline Cervical cancer & $1308(722)$ \\
\hline Colorectal cancer & $2931(3287)$ \\
\hline NPC & $1652(486)$ \\
\hline Others & $2842(6751)$ \\
\hline \multicolumn{2}{|l|}{ By type of health facility } \\
\hline Private & $5341(10814)$ \\
\hline Government & $2177(3410)$ \\
\hline \multicolumn{2}{|c|}{ By history of visit at private health facility } \\
\hline Visited & $2870(5256)$ \\
\hline Not visited & $1494(822)$ \\
\hline \multicolumn{2}{|c|}{ Have no history of visit at private health facility by type of cancer } \\
\hline Breast cancer & $1658(923)$ \\
\hline Cervical cancer & $1074(581)$ \\
\hline Colorectal cancer & $2144(806)$ \\
\hline NPC & - \\
\hline Others & $1446(653)$ \\
\hline \multicolumn{2}{|c|}{ Have a history of visit at private health facility by type of cancer } \\
\hline Breast cancer & 2799 (3479) \\
\hline Cervical cancer & $1616(783)$ \\
\hline Colorectal cancer & $3150(3673)$ \\
\hline NPC & $1652(486)$ \\
\hline Others & $3454(8035)$ \\
\hline Catastrophic & $2495(4745)$ \\
\hline \multicolumn{2}{|l|}{ By their catastrophic level } \\
\hline Not catastrophic & $1990(2324)$ \\
\hline \multicolumn{2}{|l|}{ By gender } \\
\hline Male & $2704(5293)$ \\
\hline Female & $2243(3822)$ \\
\hline \multicolumn{2}{|l|}{ By marital status } \\
\hline Single & $3751(8255)$ \\
\hline Divorced & $2598(1873)$ \\
\hline Married & $2244(3736)$ \\
\hline Widowed & $1174(761)$ \\
\hline \multicolumn{2}{|l|}{ By residence } \\
\hline Addis Ababa & $2223(4310)$ \\
\hline Out of Addis Ababa & $2464(4236)$ \\
\hline \multicolumn{2}{|l|}{ By educational level } \\
\hline No formal education & $1674(913)$ \\
\hline Grade 1-8 & $1685(771)$ \\
\hline Grade 9-12 & 2306 (2986) \\
\hline College/certificate and above & $3310(6716)$ \\
\hline
\end{tabular}


Table 3 Mean overall expenditure per patient by different subgroups among patients attending cancer treatment services in Addis Ababa, Ethiopia 2018 (Continued)

\begin{tabular}{ll}
\hline Subgroup variables & Mean overall expenditure per patient (SD) (\$) \\
\hline By occupational status & $3229(8288)$ \\
Retired & $2455(3024)$ \\
Employed (private/government) & $2396(2038)$ \\
Own private business & $2164(4488)$ \\
Housewife/Husband & $1842(1022)$ \\
Others &
\end{tabular}

---: There are no cases of NPC with history of visit at private health facility; SD Standard deviation; 1 US\$ $=23.41$ Ethiopian Birr (ETB)

of CHE used, our finding was higher as compared to other studies reported from Asian countries (47.867.9\%) [30-32]. But, this was lower compared to patients with breast cancer in India (84\%) [33]. This high level of CHE might be due to the limited number of treatment and diagnostic centers available, which can increase its side expenditures and frequent stock out of prescribed medicines. A higher level of CHE was reported due to cancer care when compared to care for cardiovascular patients in Ethiopia (27.0\%) [20].

Similarly, with the threshold set at 10\% household consumption expenditure, the level of CHE documented in the present study was higher compared to a study conducted in households of persons with depression and high disability, and severe mental disorder [34, 35]. Limited geographic access to cancer care centers and higher cost of medicines might be the reasons for such difference. The government provide oncology medicines in a $50 \%$ subsidized price, but there is still an imbalance in the demand and supply of drugs [36]. As a result, patients have no choice but to buy from the private medicine retail outlets, which might result in patients' households to face another intolerable financial burden.

The level of CHE also showed variation among income quintiles, although it was not statistically significant. Other studies revealed that the lowest income category was highly associated with catastrophic expenditure [32, 37, 38]. However, in the present study, the fourth income strata faced with a higher level of CHE than the others. Patients with lower incomes might not visit and purchase expensive services if the services aren't available at affordable price. However, when the disease condition gets complicated these fourth income quintiles might pay while facing catastrophic expenditure.

The level of CHE and self-reported financial pressure was simultaneously high and approximately parallel. This self-reported unmanageable rate of financial burden documented in our study was lower than that recorded in China (75\%) [19]. However, it was higher than the study finding in the United States, which showed a financial distress level of $47 \%$ [39]. The presence of financial sharing policy and the difference in the income status of the population would influence the level of financial distress across countries, indicating the need to institute risk pooling and sharing mechanisms.

The patients' age and increased the number of cycles of chemotherapy was among the predicting factors of CHE. Other studies showed similar finding $[16,25]$. Increasing $\mathrm{CHE}$ with age could be attributed to disease complication and income sources. The numbers of cycles of chemotherapy is also an indicator of the stage of the disease. The possible treatment failure and the need for either re-treatment or new treatments would force the patients to incur additional expenses, thereby increasing the financial burden [40-42]. Although not statistically significant, patients with a history of visit at a private health facility, patients with colorectal cancer, patients attending a private health facility, male, single, and patients residing out of Addis Ababa reportedly encountered with higher-level cancer care expenditure.

Similar to other studies, patient' households use more than one coping strategies to overcome their financial distress, with the most prevalent being borrowing, selling assets, spending savings, and financial aid [43]. Among those, household saving was the primary coping strategy used in the study, which was also documented in other studies [7, 20, 44]. However, some other studies indicated that borrowing and selling assets were the major coping strategies [27, 44-46]. Variations in economic status and saving culture across households can affect the coping mechanism of patients' families [47, 48].

Although the study comes with those results it was not without limitations. First, due to the nature of data collection technique, recall bias could be a problem. Obtaining reliable information on the household annual income and expenditure was also another challenge. Since the study design was hospital-based, a significant number of populations may not have access because of affordability and limited availability. 
Table 4 Factors associated with CHE and proportion of CHE among subgroups of patients attending cancer treatment services in Addis Ababa, Ethiopia 2018

\begin{tabular}{|c|c|c|c|}
\hline Variables & $\begin{array}{l}\text { Proportion of CHE } \\
\mathrm{N}, \%(95 \% \mathrm{Cl})\end{array}$ & COR $(95 \% \mathrm{Cl})$ & AOR $(95 \% \mathrm{Cl})$ \\
\hline \multicolumn{4}{|l|}{ Type of Health Facility } \\
\hline Private & $16,76.2(53.3-89.9)$ & $1.11(0.39-3.11)$ & $1.29(0.38-4.40)$ \\
\hline Public $^{a}$ & $246,74.3(69.3-78.7)$ & 1.00 & 1.00 \\
\hline \multicolumn{4}{|l|}{ Type of cancer } \\
\hline Breast cancer & $94,72.3(63.9-79.4)$ & $1.10(0.55-2.14)$ & $0.72(0.31-1.66)$ \\
\hline Colorectal cancer & $32,69.6(54.7-81.2)$ & $0.95(0.41-2.21)$ & $0.68(0.22-2.10)$ \\
\hline NPC & $11,84.6(53.3-96.3)$ & $2.28(0.46-11.40)$ & $2.92(0.41-20.7)$ \\
\hline Others & $84,80.0(71.2-86.6)$ & $1.66(0.79-3.48)$ & $1.33(0.52-3.43)$ \\
\hline Cervical cancer ${ }^{a}$ & $41,70.7(57.6-81.0)$ & 1.00 & 1.00 \\
\hline \multicolumn{4}{|l|}{ Cycles of chemotherapy taken } \\
\hline$\leq 3$ cycles & $71,73.2(63.4-81.1)$ & $1.21(0.54-2.74)$ & $1.25(0.47-3.35)$ \\
\hline $4-6$ cycles & $113,72.9(65.3-79.3)$ & $1.20(0.55-2.57)$ & $1.31(0.52-3.43)$ \\
\hline$>6$ cycles & $51,83.6(72.0-91.0)$ & $2.27(0.87-5.92)$ & $3.64(1.11-11.92)$ \\
\hline On other treatment options ${ }^{a}$ & $27,69.2(53.0-81.8)$ & 1.00 & 1.00 \\
\hline \multicolumn{4}{|l|}{ Private health facility visit } \\
\hline No & $97,75.2(67.0-82.0)$ & $1.06(0.65-1.75)$ & $1.19(0.66-2.13)$ \\
\hline$Y_{e s}^{a}$ & $165,74.0(67.8-79.3)$ & 1.00 & 1.00 \\
\hline Age & - & $1.01(0.99-1.03)$ & $1.03(1.01-1.06)$ \\
\hline Household size & - & $0.95(0.87-1.04)$ & $0.95(0.85-1.07)$ \\
\hline \multicolumn{4}{|l|}{ Gender } \\
\hline Male & $72,76.6(66.9-84.1)$ & $1.17(0.67-2.03)$ & $1.01(0.41-2.46)$ \\
\hline Female $^{\mathrm{a}}$ & 190, $73.6(67.9-78.7)$ & 1.00 & 1.00 \\
\hline \multicolumn{4}{|l|}{ Marital status } \\
\hline Single & $26,76.5(59.2-87.9)$ & $1.14(0.50-2.63)$ & $1.91(0.60-6.13)$ \\
\hline Divorced & $14,73.7(49.4-88.9)$ & $0.98(0.34-2.82)$ & $1.20(0.34-4.20)$ \\
\hline Widowed & $11,78.6(49.2-93.2)$ & $1.29(0.35-4.74)$ & $1.48(0.31-6.96)$ \\
\hline Married $^{\mathrm{a}}$ & $211,74.0(68.6-78.8)$ & 1.00 & 1.00 \\
\hline \multicolumn{4}{|l|}{ Residence } \\
\hline Out of Addis Ababa & $158,75.6(69.3-81.0)$ & $1.16(0.72-1.89)$ & $1.07(0.61-1.86)$ \\
\hline In Addis Ababaa & $104,72.7(64.8-79.4)$ & 1.00 & 1.00 \\
\hline \multicolumn{4}{|l|}{ Level of Education } \\
\hline No formal education & $93,73.2(64.8-80.2)$ & $0.93(0.53-1.64)$ & $0.47(0.18-1.26)$ \\
\hline Grade 1-8 & $28,82.4(65.5-92.0)$ & $1.59(0.60-4.20)$ & $0.99(0.30-3.26)$ \\
\hline Grade 9-12 & $50,72.5(60.7-81.8)$ & $0.89(0.46-1.75)$ & $0.59(0.25-1.42)$ \\
\hline College and above ${ }^{a}$ & $91,74.6(66.1-81.6)$ & 1.00 & 1.00 \\
\hline \multicolumn{4}{|l|}{ Occupation } \\
\hline Own private business & $39,79.6(65.8-88.7)$ & $1.40(0.62-3.20)$ & $2.21(0.79-6.17)$ \\
\hline Housewife/Husband & $107,77.0(69.2-83.3)$ & $1.21(0.67-2.17)$ & $2.30(0.87-6.01)$ \\
\hline Retired & $22,61.1(44.5-75.6)$ & $0.56(0.25-1.26)$ & $0.48(0.17-1.33)$ \\
\hline Others & 19, $73.1(52.8-86.8)$ & $0.98(0.37-2.58)$ & $1.17(0.30-4.55)$ \\
\hline Employed private/government $^{a}$ & $75,73.5(64.1-81.2)$ & 1.00 & 1.00 \\
\hline \multicolumn{4}{|l|}{ Income quintile } \\
\hline Lowest & $49,66.2(54.6-76.1)$ & $1.04(0.52-2.09)$ & $0.85(0.18-3.86)$ \\
\hline
\end{tabular}


Table 4 Factors associated with CHE and proportion of CHE among subgroups of patients attending cancer treatment services in Addis Ababa, Ethiopia 2018 (Continued)

\begin{tabular}{lllr}
\hline Variables & $\begin{array}{l}\text { Proportion of CHE } \\
\text { N, \% }(95 \% \text { Cl) }\end{array}$ & COR (95\% Cl) & AOR (95\% Cl) \\
\hline Second & $58,78.4(67.4-86.4)$ & $1.93(0.92-4.06)$ & $1.30(0.38-4.38)$ \\
Middle & $50,78.1(66.2-86.7)$ & $1.91(0.88-4.12)$ & $1.21(0.41-3.57)$ \\
Fourth & $60,84.5(74.0-91.3)$ & $2.91(1.29-6.55)$ & $2.66(0.97-7.29)$ \\
Highest $^{\mathrm{a}}$ & $45,65.2(53.2-75.6)$ & 1.00 & 1.00 \\
Expenditure quintile & & $1.27(0.58-2.58)$ & $1.49(0.30-7.34)$ \\
Lowest $_{\text {Second }}$ & $48,67.6(55.8-77.5)$ & $1.58(0.74-3.38)$ & $1.52(0.42-5.50)$ \\
Middle & $51,72.8(61.2-82.1)$ & $3.65(1.53-8.68)$ & $3.04(0.91-10.17)$ \\
Fourth & $62,86.1(75.9-92.4)$ & $2.19(1.02-4.67)$ & $1.49(0.52-4.33)$ \\
Highest $^{\mathrm{a}}$ & $67,78.8(68.7-86.3)$ & 1.00 & 1.00 \\
\hline
\end{tabular}

a: reference group; Bold: significant association at $95 \% \mathrm{Cl}(\mathrm{COR}$ and $\mathrm{AOR}) ; \mathrm{AOR}$ Adjusted odds ratio; COR:Crude odds ratio

Hence, most patients' households included in the study were more likely to have a relatively higher income.

\section{Conclusion}

Based on a $10 \%$ threshold of annual household income, a substantial number of patients with cancer are exposed to a catastrophic level of healthcare expenditure with considerable medical cost. Predominantly, patients with increased cycles of chemotherapy and older age were incurring a catastrophic level of healthcare expenditure. Household saving was the primary coping strategy; however, a significant number of patients' households had been forced to look for other coping mechanisms. The efficient mobilization of the health insurance scheme is urgently needed to ensure financial risk protection and realize universal health coverage for patients with cancer. Increased tax funding and/or other better prepayment mechanisms should also be considered while mobilizing the already introduced health insurance scheme.

Table 5 Coping strategies used by patients' households for the financial constraints of cancer care in Addis Ababa, Ethiopia 2018

\begin{tabular}{lll}
\hline Coping strategies & $\mathrm{N}$ & \% (95\% Cl) \\
\hline Savings $^{\mathrm{a}}$ & 301 & $85.5(81.4-88.8)$ \\
Financial support $^{\mathrm{b}}$ & 151 & $43.0(38.0-48.1)$ \\
Selling assets $^{c}$ & 42 & $12.0(8.9-15.8)$ \\
Borrowings $^{\mathrm{d}}$ & 30 & $8.5(6.0-12.0)$
\end{tabular}

${ }^{\mathrm{a}}$ : It includes any method of household savings and sources from the household member (including Eqqub and Iddir)

b: Financial source or support received from relatives, non-governmental organizations, religious organizations and others source of payments which are nonrefundable

c: Any means of payment made by selling household assets like land, property, livestock, jewellery and other household items

${ }^{d}$ : Borrowings took from financial institutions and individuals

NB: Frequencies and percentage would not be added up because multiple responses were possible

\section{Supplementary information}

Supplementary information accompanies this paper at https://doi.org/10. 1186/s12889-020-09137-y.

Additional file 1. Table S1 Data collection instrument

\section{Abbreviations}

AOR: Adjusted Odds Ratio; CHE: Catastrophic Health Expenditure; COR: Crude Odds Ratio; Inter-Quartile Range: IQR; OOP: Out of Pocket; SD: Standard Deviation; TASH: Tikur Anbessa Specialized Hospital; WHO: World Health Organization

\section{Acknowledgements}

We would like to thank the data collectors (Nurses), Pharmacists and Physicians for their humbled support and involvement during the data collection process. Besides, we would like to extend our special gratitude to the study participants for their willingness to participate and supported the realization of the work.

\section{Authors' contributions}

GGK, GBG and TGF conceptualized and designed the study. GGK made substantial contribution in the data collection, data analysis, data interpretation, and writing of the manuscript. GBG, TGF, YH, and AAW contributed to the data analysis, data interpretation, and evaluation of the manuscript. All authors read and approved the final version of the manuscript.

\section{Funding}

The Addis Ababa University Graduate program funded the study, and it had no role in the study design, data collection, and analysis, decision to publish, or preparation of the manuscript.

\section{Availability of data and materials}

The dataset should be accessible from the corresponding author on a reasonable request.

\section{Ethics approval and consent to participate}

The Institutional Ethics Review Committee of the School of Pharmacy, Addis Ababa University approved the study (Ref: ERB/SOP/01/10/2018), and permission was secured from all study hospitals. Written consent was obtained from the participants before the beginning of the interview. Questionnaires were coded to prevent any identification to ensure participants' anonymity and stored in the lockable cabinet except access to the study team to ensure participants confidentiality.

Consent for publication

Not applicable. 


\section{Competing interests}

The authors declare that they have no competing interests.

\section{Author details}

'Department of Pharmacy, College of Health Sciences, Aksum University, Aksum, Tigray, Ethiopia. ${ }^{2}$ Department of Pharmaceutics and Social Pharmacy, School of Pharmacy, College of Health Sciences, Addis Ababa University, Addis Ababa, Ethiopia. ${ }^{3}$ School of Public Health, College of Health Sciences, Addis Ababa University, Addis Ababa, Ethiopia. ${ }^{4}$ School of Medicine, College of Health Sciences, Addis Ababa University, Addis Ababa, Ethiopia.

\section{Received: 19 September 2019 Accepted: 17 June 2020}

Published online: 22 June 2020

\section{References}

1. Buigut S, Ettarh R, Amendah DD. Catastrophic health expenditure and its determinants in Kenya slum communities. Int J Equity Health. 2015;14:1-12.

2. Abul Naga R, Lamiraud K. Catastrophic health expenditure and household well-being; 2011. p. 1-20.

3. Puteh S, Almualm Y. Catastrophic health expenditure among developing countries. Health Syst Policy Res. 2017:4:1-5.

4. Wagstaffa A, van Doorslaerc E. Catastrophe and impoverishment in paying for health care: with applications to Vietnam 1993-98. Health Econ. 2003;12: 921-34.

5. Xu K, Evans DB, Kawabata K, Zeramdini R, Klavus J, Murray CJ. Household catastrophic health expenditure: a multicountry analysis. Lancet. 2003;362:111-7.

6. O'Donnell O, van Doorslaer E, Rannan-Eliya RP, Somanathan A, Garg CC, Hanvoravongchai $P$, et al. Explaining the incidence of catastrophic expenditures on health care: comparative evidence from Asia. Equitap. 2005;1-28.

7. Engelgau MM, Karan A, Mahal A. The economic impact of noncommunicable diseases on households in India. Glob Health. 2012;8:1-10.

8. DeSantis C, Naishadham D, Jemal A. Cancer statistics for African Americans, 2013. CA Cancer J Clin. 2013;63:151-66.

9. WHO. The World Health Report: Research for Universal Health Coverage. International Agency for Research on Cancer. Geneva: World Health Organization; 2013. p. 1-146.

10. Wagstaff A, Flores G, Hsu J, Smitz MF, Chepynoga K, Buisman LR, et al. Progress on catastrophic health spending in 133 countries: a retrospective observational study. Lancet Glob Health. 2018;6:1-11.

11. John R, Ross H. The global economic cost of cancer. Atlanta: American Cancer Society and Livestrong; 2010. p. 1-10.

12. Torre LA, Siegel RL, Ward EM, Jemal A. Global cancer incidence and mortality rates and trends. An update. Cancer Epidemiol Prev Biomarkers. 2016;25:16-27.

13. $\mathrm{FMOH}$. Health insurance strategy, planning and programming department. Addis Ababa, Ethiopia: Federal Ministry of Health; 2008. p. 1-17.

14. USAID. Ethiopia's Community-based Health Insurance: A Step on the Road to Universal Health Coverage; 2015. p. 2-11.

15. Hailu A, Mariam DH. Patient side cost and its predictors for cervical cancer in Ethiopia: a cross sectional hospital based study. BMC Cancer. 2013;13:1-8.

16. Mamo G, Worku A, Lemma S, Demas T. Cost of illness of breast Cancer patients on chemotherapy in Addis Ababa public hospitals, the case of Tikur Anbessa specialized teaching Hospital-cross-sectional types of study. Health Econ Outcome Res Open Access. 2017;3:1-5.

17. Daniel WW. Biostatistics: a foundation for analysis in the health sciences. New York: Wiley. Inc; 1995. p. 192-3.

18. World Health Organization. SAGE Survey Manual: The WHO Study on Global AGEingand Adult Health (SAGE). Geneva: World Health Organization; 2006. p. 1-226.

19. Huang HY, Shi JF, Guo LW, Bai YN, Liao XZ, Liu GX, et al. Expenditure and financial burden for the diagnosis and treatment of colorectal cancer in China: a hospital-based, multicenter, cross-sectional survey. Chin J Cancer. 2017:36:1-15.

20. Tolla MT, Norheim OF, Verguet S, Bekele A, Amenu K, Abdisa SG, et al. Outof-pocket expenditures for prevention and treatment of cardiovascular disease in general and specialised cardiac hospitals in Addis Ababa, Ethiopia: a cross-sectional cohort study. BMJ Glob Health. 2017;2:1-10.

21. Xu K, Evans DB, Carrin G, Aguilar-Rivera AM, Musgrove P, Evans T. Protecting households from catastrophic health spending. Health Aff. 2007;26:972-83.

22. Barber JA, Thompson SG. Analysis of cost data in randomized trials: an application of the non-parametric bootstrap. Stat Med. 2000;19:3219-36.
23. White IR, Thompson SG. Choice of test for comparing two groups, with particular application to skewed outcomes. Stat Med. 2003:22:1205-15.

24. Manikandan S. Measures of central tendency: median and mode. J Pharmacol Pharmacother. 2011:2:214-5.

25. Newton JC, Johnson CE, Hohnen H, Bulsara M, Ives A, McKiernan S, et al. Out-of-pocket expenses experienced by rural Western Australians diagnosed with cancer. Support Care Cancer. 2018;26:3543-52.

26. World Bank. Ethiopia public expenditure review 2015. Washington, DC: World Bank Group; 2016.

27. Pourreza A, Harirchi I, Bazyar M. Differentiation of out-of-pocket expenditures in cancer patients; a case study in the cancer institute of Iran. Evid Based Health Policy Manage Econ. 2017;1:65-73.

28. Stintzing S. Management of colorectal cancer. F1000Prime Rep. 2014;6:108 Published 2014 Nov 4. https://doi.org/10.12703/P6-108, https://www.ncbi. nlm.nih.gov/pmc/articles/PMC4229728/.

29. Choi JW, Cho KH, Choi Y, Han KT, Kwon JA, Park EC. Changes in economic status of households associated with catastrophic health expenditures for cancer in South Korea. Asian Pac J Cancer Prev. 2014;15:2713-7.

30. Azzani M, Yahya A, Roslani AC, Su TT. Catastrophic health expenditure among colorectal Cancer patients and families: a case of Malaysia. Asia Pacific J Public Health. 2017;29:485-94.

31. Delavari H, Keshtkaran A, Setoudehzadeh F. Catastrophic health expenditures and coping strategies in households with cancer patients in shiraz Namazi hospital. Middle East J Cancer. 2014;5:13-22.

32. Group AS. Catastrophic health expenditure and 12-month mortality associated with cancer in Southeast Asia: results from a longitudinal study in eight countries. BMC Med. 2015;13:1-13.

33. Jain M, Mukherjee K. Economic burden of breast cancer to the households in Punjab, India. Int J Med Public Health. 2016;6:13-8.

34. Hailemichael Y, Hanlon C, Tirfessa K, Docrat S, Alem A, Medhin G, et al. Catastrophic health expenditure and impoverishment in households of persons with depression: a cross-sectional, comparative study in rural Ethiopia. BMC Public Health. 2019;19:1-13.

35. Hailemichael Y, Hailemariam D, Tirfessa K, Docrat S, Alem A, Medhin G, et al. Catastrophic out-of-pocket payments for households of people with severe mental disorder: a comparative study in rural Ethiopia. Int J Ment Heal Syst. 2019;13:1-13.

36. Tikur Anbessa Specialized Hospital. Oncology pharmacy. Addis Ababa, Ethiopia. (Accessed on 12 May 2018).

37. Bernard DS, Farr SL, Fang Z. National estimates of out-of-pocket health care expenditure burdens among nonelderly adults with cancer: 2001 to 2008. J Clin Oncol. 2011;29:2821-6.

38. Tripathy J, Prasad B, Shewade H, Kumar A, Zachariah R, Chadha S, et al. Cost of hospitalisation for non-communicable diseases in India: are we pro-poor? Trop Med Int Health. 2016;21:1019-28.

39. Meisenberg BR, Varner A, Ellis E, Ebner S, Moxley J, Siegrist E, et al. Patient attitudes regarding the cost of illness in cancer care. Oncologist. 2015;20:1199-204.

40. Blumen H, Fitch K, Polkus V. Comparison of treatment costs for breast cancer, by tumor stage and type of service. Am Health Drug Benefits. 2016;9:23-32.

41. Kakushadze Z, Raghubanshi R, Yu W. Estimating cost savings from early cancer diagnosis. Data. 2017;2:1-16.

42. Kutikova L, Bowman L, Chang S, Long SR, Obasaju C, Crown WH. The economic burden of lung cancer and the associated costs of treatment failure in the United States. Lung Cancer. 2005;50:143-54.

43. Chakrabarty J, Pai MS, Ranjith V, Fernandes D. Economic burden of cancer in India. Indian J Public Health. 2017;8:137-41.

44. Bogale T, Mariam DH, Ali A. Costs of illness and coping strategies in a coffee-growing rural district of Ethiopia. J Health Popul Nutr. 2005;23:192-9.

45. Kruk ME, Goldmann E, Galea S. Borrowing and selling to pay for health care in low-and middle-income countries. Health Aff. 2009;28:1056-66.

46. Leive A, Xu K. Coping with out-of-pocket health payments: empirical evidence from 15 African countries. Bull World Health Organ. 2008;86:849-56C.

47. Mirach TH, Hailu YM. Determinants of household saving in Ethiopia: a case of North Gondar zone Amhara regional state. Int J Dev Econ Sustainability. 2014;2:37-49.

48. Zwane T, Greyling L, Maleka M. The determinants of household saving in South Africa: a panel data approach. Int Bus Econ Res J. 2016;15:209-18.

\section{Publisher's Note}

Springer Nature remains neutral with regard to jurisdictional claims in published maps and institutional affiliations. 